\title{
First Case of Subcutaneous Zygomycosis Caused by Saksenaea vasiformis in India
}

\author{
A.A. Padhye, G. Koshi, V. Anandi, J. Ponniah, \\ V. Sitaram, M. Jacob, R. Mathai, L. Ajello, \\ and F.W. Chandler
}

The first case of subcutaneous zygomycotic infection caused by Saksenaea vasiformis in a rice mill worker from India is described. The infection, confined to the man's left foot, showed multiple draining sinuses, inflammation, and intermittent low-grade fever following a crushing injury when a log fell on his foot. Histopathologic examination of two biopsy specimens, taken at 3-wk intervals, revealed the presence of broad, sparsely septate, branched, hyaline hyphae characteristic of a zygomycete. When they were grown on a nutritionally deficient medium, two cultures isolated from the biopsied tissues formed numerous, vase-shaped sporangia typical of $\underline{S}$. vasiformis. Necrosis of the affected area led to amputation of the fore part of the foot. A split thickness graft was well accepted, and treatment with potassium iodide, following the graft, cured the infection.

\section{INTRODUCTION}

The pathogen Saksenaea vasiformis was first isolated and described, as a new genus and species, from forest soils collected in India by Saksena in 1953 (Saksena, 1953). Since that time, this zygomycete, characterized by the production of vase-shaped sporangia, has been isolated from soils from Honduras (Goos, 1963), Israel (Joffe and Borut, 1966), Panama (Farrow, 1954), and the United States (Hodges, 1962). The first human infection due to $S$. vasiformis was described by Ajello et al. in the United States (Ajello et al. 1976). Since then, 11 additional cases of cutaneous zygomycosis have been described in the literature from Australia, Colombia, Iraq, Israel, and the United States (Table 1). We are aware of two other cases from the United States (included in Table 1) of zygomycotic infections caused by $S$. vasiformis that are not yet described in the literature. Despite the discovery of this fungus in Indian soil, S. vasiformis had never been encountered as an etiologic agent of zygomycosis in India. For this reason, we describe the first case of localized cutaneous zygomycotic infection caused by $S$. vasiformis in a man from south India.

From the Division of Mycotic Diseases (A.A.P., L.A.) and Division of Host Factors (F.W.C.), Center for Infectious Diseases, Centers for Disease Control, Public Health Service, U.S. Department of Health and Human Services, Atlanta, Georgia; and Departments of Microbiology (G.K., V.A.), Pathology (J.P.), Surgery (V.S.), and Dermatology (M.J., R.M.), Christian Medical College Hospital, Vellore, India.

Address reprint requests to: Dr. Arvind A. Padhye, Division of Mycotic Diseases, Center for Infectious Diseases, Building 5, B-13 (G-11). Centers for Disease Control, Atlanta, GA 30333.

Received December 3, 1987; revised and accepted February 22, 1988. 


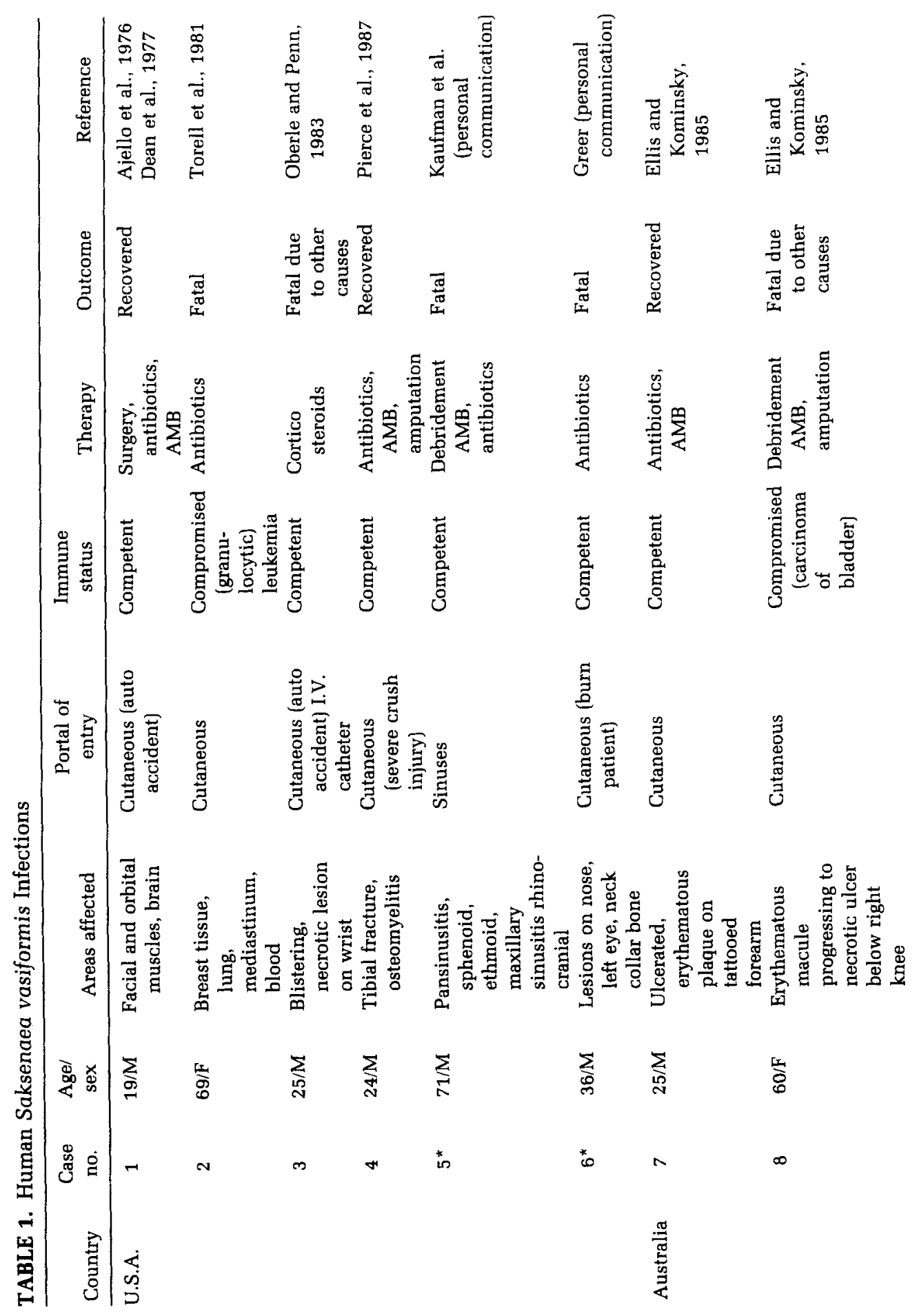




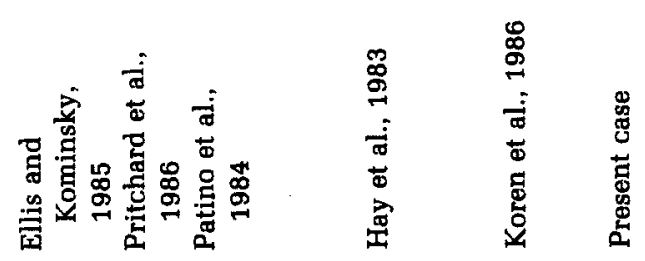

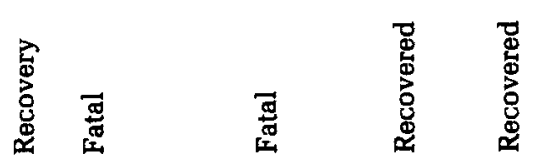

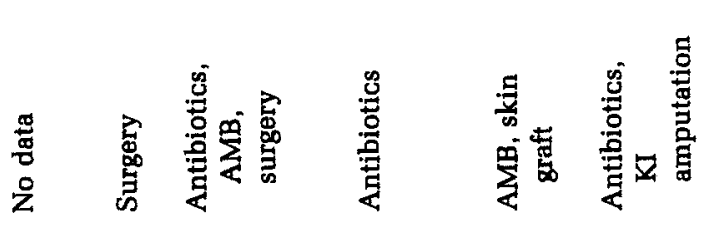

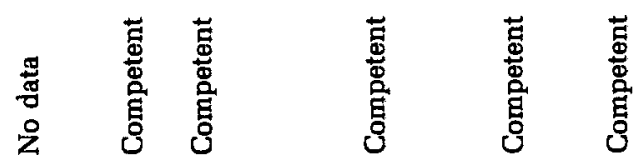

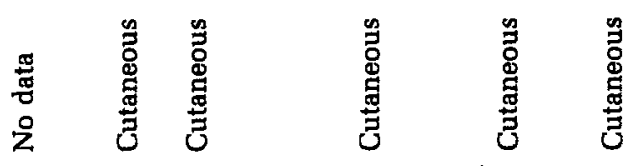

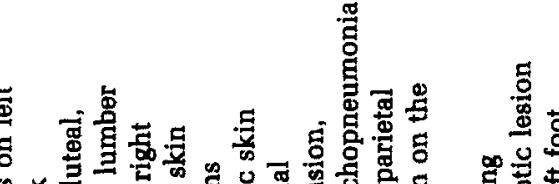

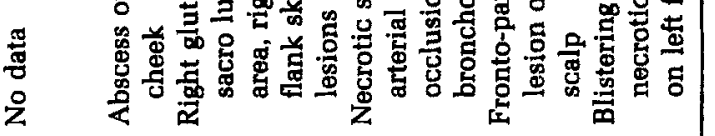

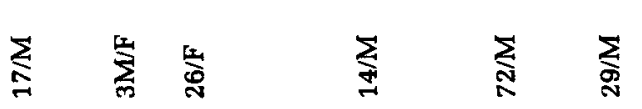

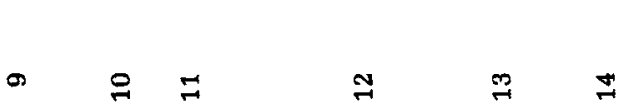

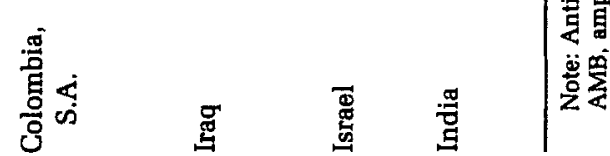




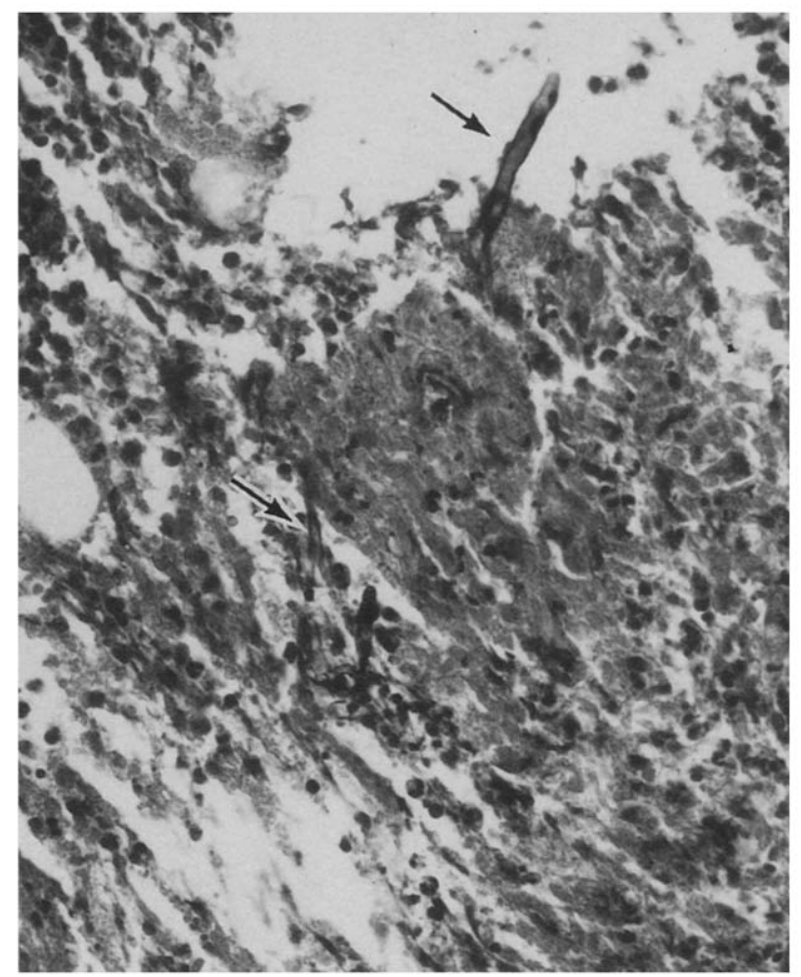

FIGURE 1. Cutaneous zygomycosis caused by Saksenaea vasiformis. Hyphal fragments (arrows) are embedded in an area of suppurative necrosis. The overlying epidermis was ulcerated. $\times 340$; hematoxylin and eosin stain $(\mathrm{H} \& \mathrm{E})$.

\section{CASE REPORT}

A 29-year-old man, a rice mill worker, was first seen in September 1986 with complaints of painful swelling of the left foot with multiple discharging sinuses and intermittent low-grade fever, with a duration of $18 \mathrm{mo}$. His complaints began following a crushing injury when a log fell on his left foot. The abrasion over the dorsum of the foot healed slowly, but the foot gradually became swollen, and bullae appeared, which then broke down and discharged pus. The local physician diagnosed the infection as a mycetoma, and the patient was initially treated with dapsone. Because a tuberculoid granuloma was diagnosed elsewhere, he was then treated with streptomycin and isoniazid for 6 mo.

On admission to the Christian Medical College Hospital in September 1986, general systemic examination revealed no other abnormalities except the left foot, which was swollen up to the ankle and was "woody hard." The advancing margin of the swelling was delineated, as an erythematous swollen border extending to the insole medially and to the ankle proximally. The skin was hyperpigmented and showed multiple areas of oozing and superficial ulcerations covered with yellowish exudate and brownish adherent crust. Regional lymph nodes were enlarged, discrete, and tender. Roentgenographic examination showed no bone involvement.

The initial biopsy report suggested zygomycosis. Therapy with $1 \mathrm{~g}$, once daily, of oral potassium iodide (KI) was started. Within $3 \mathrm{hr}$ of administering the first dose of $\mathrm{KI}$, the patient complained of an intense pain in the foot; and within $24 \mathrm{hr}$, the erythematous border of the foot became very red and swollen. The pain could not 


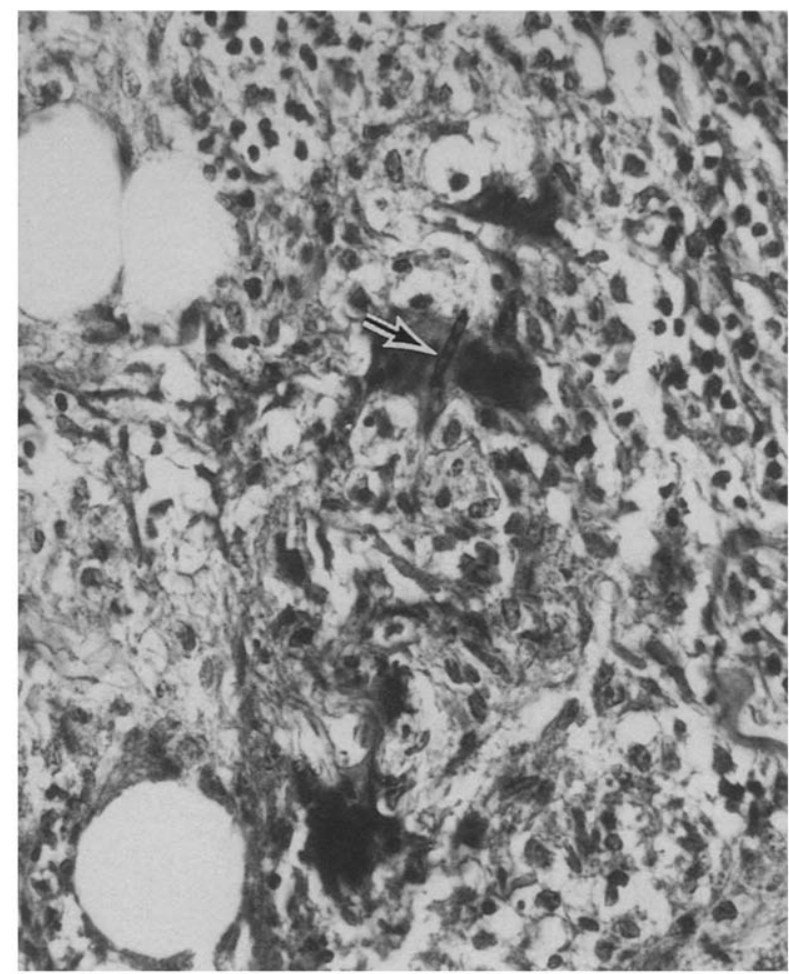

FIGURE 2. Hyphal fragments of S. vasiformis (arrow) within the cytoplasm of a multinucleate giant cell. $\times 340$; Gomori's methenamine silver (GMS) with H \& E counterstain.

be controlled with routine analgesics. Continuation of the treatment with KI for 3 more days resulted in intensification of the pain. The swelling and cutaneous erythema increased over the involved region and several contiguous areas. On the fourth day, the patient became febrile. At this time, because some form of Jarisch-Herxheimer reaction to KI was suspected, the treatment was stopped. To control the severe inflammation, prednisolone and broad-spectrum antibiotics were administered. The pain and erythema soon subsided. Four days later, when KI treatment was resumed, the patient again experienced severe pain. The ulcers were more necrotic, and debridement of the ulcers was carried out under general anesthesia. Examination of the excised tissue reconfirmed that the infection was due to a zygomycete.

The patient was treated with dry dressings and underwent debridement again after 18 days. In spite of repeated dressings, the area distal to the metatarsals did not respond to treatment. Hence, a transmetatarsal amputation was performed. One month after surgery, treatment with $\mathrm{KI}$ was reinstituted. The dosage was gradually increased up to $10 \mathrm{~g}$ once a day. Repeat biopsy from the amputated end of the foot after $6 \mathrm{wk}$ of treatment with KI showed no evidence of fungal infection. A split-thickness skin graft was applied 2 mo after surgery. At the time of discharge, the graft was accepted well, and treatment with KI was continued at $4 \mathrm{~g}$ per day. The patient was advised to return for follow-up.

Two biopsy specimens were received at an interval of $3 \mathrm{wk}$. The first specimen consisted of skin and subcutaneous tissue containing part of a sinus tract. The second specimen was a disarticulated toe, where the dorsal surface near the nail showed an elevated ulcer. Direct examinations in $\mathrm{KOH}$ mounts of the necrotic tissue received after debridement showed broad, hyaline, branched, sparsely septate hyphae with 


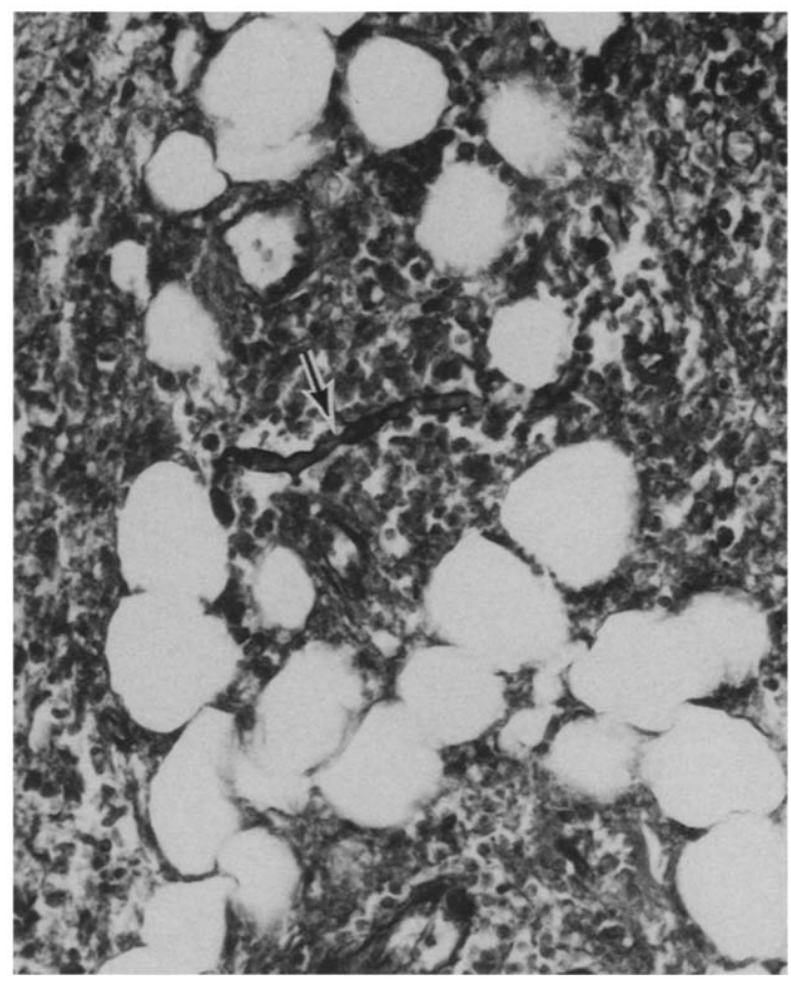

FIGURE 3. S. vasiformis in subcutaneous tissue. A broad, branched hypha (arrow) with irregular contours and infrequent septations is surrounded by mixed inflammatory cells. $\times 340$; GMS and $\mathrm{H} \& \mathrm{E}$.

intercalary swollen cells. Similar examination of the tissue from the amputated foot showed similar zygomycetous hyphae.

Two histologic slides from the first biopsied tissue and two subcultures of a white, floccose, nonsporulating, zygomycetous fungus isolated from the two biopsies were sent to the Division of Mycotic Diseases, Centers for Disease Control (CDC), Atlanta, Georgia, for specific identification.

\section{Histopathologic Findings}

Histopathologic examination of the skin, soft tissue, and bone showed ulceration of the epidermis and focal areas of hemorrhage and suppurative necrosis involving the dermis (Fig. 1). The deep dermis, subcutaneous tissue, and periosteum contained multiple discrete granulomas composed of epithelioid histiocytes and numerous multinucleate giant cells of both the foreign body and Langhans' types (Fig. 2). Some granulomas also showed central necrosis. Hyphal fragments that were hyaline, hematoxylinophilic, and poorly stained with the periodic acid Schiff's and Gomori's methenamine silver procedures were located in foci of suppurative necrosis (Fig. 1), in the necrotic centers of granulomas, and within the cytoplasm of multinucleate giant cells (Fig. 2). The pleomorphic hyphae were broad (5-20 $\mu \mathrm{m}$ in diameter), infrequently septate, and haphazardly branched. They had thin walls and irregular contours (Fig. 3). These morphologic features were characteristic of a zygomycete. Hyphal angioinvasion was evident in the dermis and subcutaneous tissue, and some 


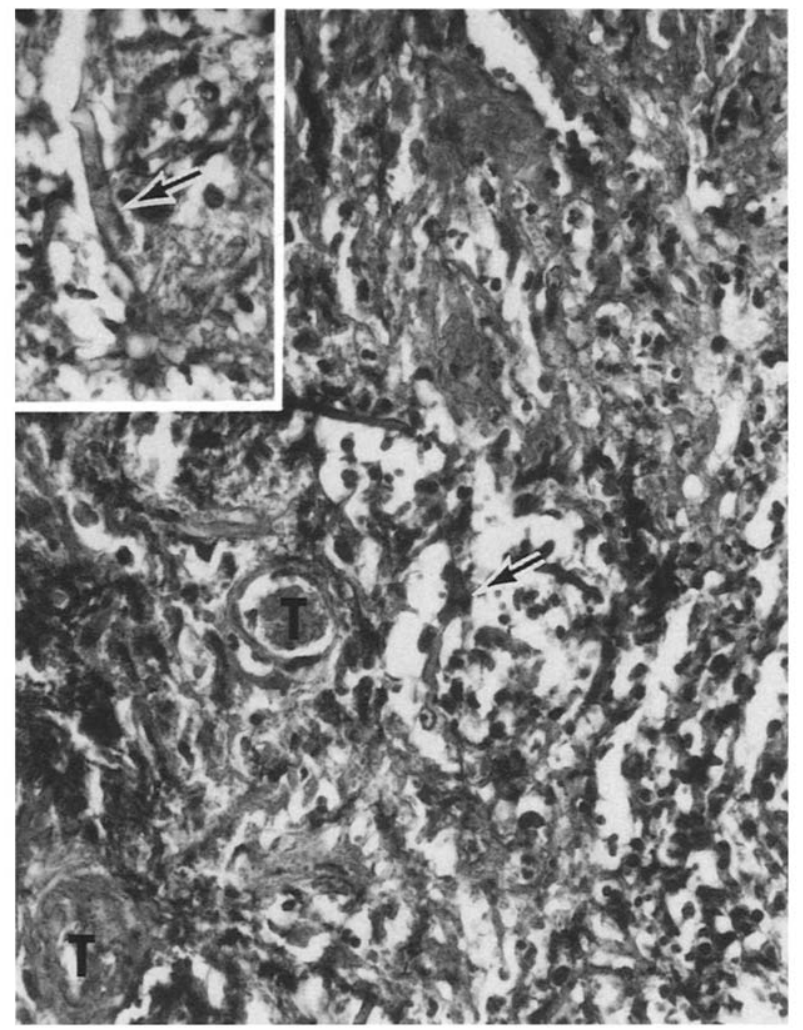

FIGURE 4. Hyphal angioinvasion by S. vasiformis (arrows). Dermal blood vessels contain thrombi (T) one of which appears to be occluded. $\times 215 ; \mathrm{H} \& \mathrm{E}$. Inset: Detail of hypha (arrow) contiguous to a large subcutaneous blood vessel. $\times 340 ; \mathrm{H} \& \mathrm{E}$.

of the blood vessels were occluded by mycotic thrombi (Fig. 4). The surrounding stroma consisted of granulation tissue infiltrated with neutrophils, lymphocytes, and plasma cells. Eosinophils were not conspicuous.

The histologic features in this case were typical of a severe, localized, cutaneous infection caused by a zygomycete in the order Mucorales. The hyphae were not bordered by Splendore-Hoeppli material, and the host reaction was not like that encountered in subcutaneous zygomycosis (caused by Basidiobolus haptosporus and Conidiobolus coronatus) (Chandler et al., 1980). No histologic evidence was found of a coexisting infection.

\section{Mycologic Findings}

When they were grown on Sabouraud dextrose agar (Difco), the two isolates failed to sporulate. Growth consisted of only broad, hyaline mycelium. Accordingly, the isolates were subcultured on corn meal sucrose yeast extract agar (Ellis and Ajello, 1982) and incubated at $25^{\circ} \mathrm{C}$ for 7 days. After 7 days of incubation, $3 \mathrm{~mm}^{3}$ agar blocks permeated with hyphae, and the accompanying aerial growth were cut from the agar plates and placed in Petri plates containing $20 \mathrm{ml}$ of sterile distilled water and 0.2 $\mathrm{ml}$ of $10 \%$ yeast extract solution. The yeast extract $(10 \%)$ in distilled water had been filter sterilized. The plates were incubated in the dark at $37^{\circ} \mathrm{C}$ and observed periodically. After 10 days, the fungus was growing as a thin film over the surface of water. 


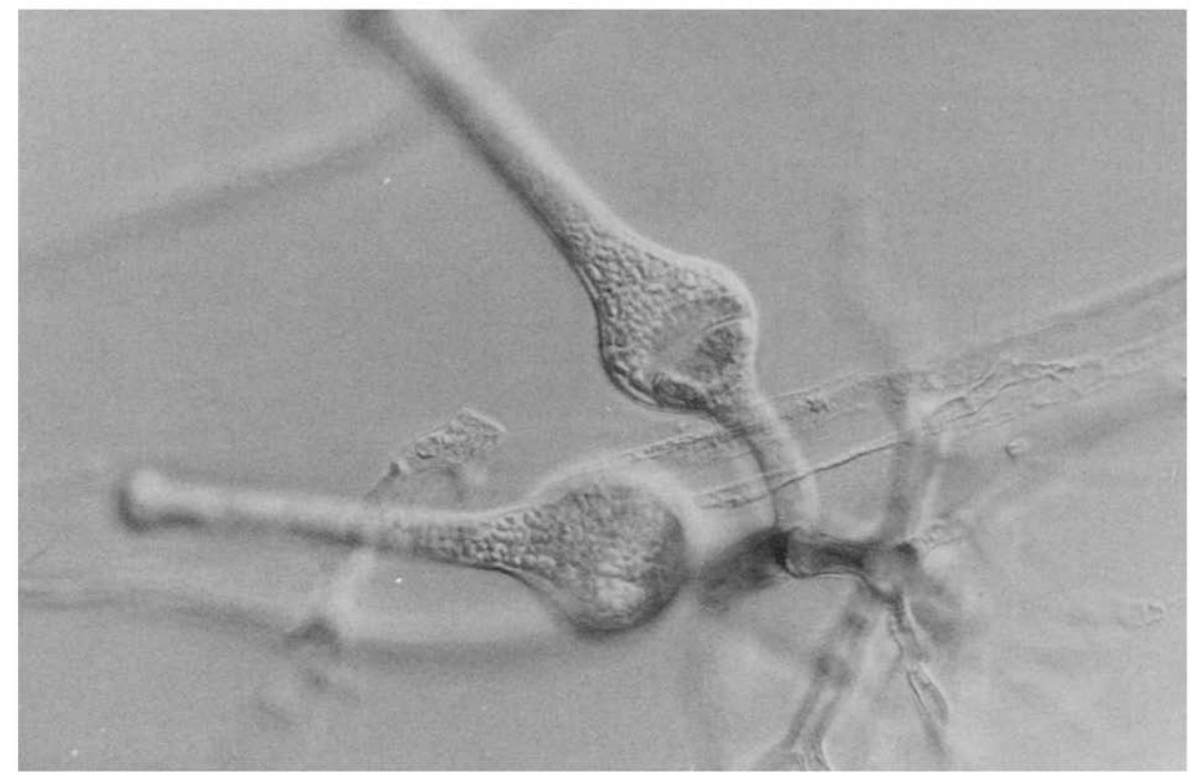

FIGURE 5. Typical vase-shaped sporangia of $S$. vasiformis (B-4455) produced in distilled water with $10 \%$ yeast extract at $37^{\circ} \mathrm{C}$ after 7 days. $\times 875$.

Microscopic examination of the growth film revealed vase-shaped sporangia characteristic of Saksenaea vasiformis (Fig. 5). The two Indian isolates have been deposited in the Division of Mycotic Diseases' culture collection under accession numbers CDC B-4455 and CDC B-4456.

\section{DISCUSSION}

In spite of the worldwide distribution of $S$. vasiformis in soil, the number of human infections caused by this zygomycete remains relatively small. Only 12 cases of cutaneous zygomycosis due to $S$. vasiformis have been described in the literature. The paucity of reports may be due to the fact that $S$. vasiformis, when it is isolated in culture, does not sporulate on routine mycological media and is mistaken for and discarded as a contaminant.

In the 12 published case reports, the portal of entry of S. vasiformis was through traumatized skin. In only one case (Kaufman et al., personal communication), the fungus gained entry through the nasal sinuses rather than through traumatized skin. The fact that $S$. vasiformis can occur in a hospital environment (Oberle and Penn, 1983) and rapidly attack the vascular system of either immunocompromised or immunocompetent patients makes it vital that a rapid and specific diagnosis be achieved so that appropriate treatment can be initiated. Since its clinical features mimicked a mycetoma, the case described here was initially misdiagnosed. Amphotericin B therapy was not considered because of the localized nature of the lesion. The administration of potassium iodide precipitated the Harisch-Herxheimer reaction. The intense pain and acute inflammation necessitated administration of steroids. The necrosis, caused by secondary pyogenic infection, led to amputation of the infected fore part of the foot. 


\section{REFERENCES}

Ajello L, Dean DF, Irwin RS (1976) The zygomycete Saksenaea vasiformis as a pathogen of humans with a critical review of the etiology of zygomycosis. Mycologia 68:52.

Chandler FW, Kaplan W, Ajello L (1980) A Colour Atlas and Textbook of the Histopathology of Mycotic Diseases. London: Wolfe Medical Publications Ltd.

Dean DF, Ajello L, Irwin RS, Woelk WK, Skarulis GJ (1977) Cranial zygomycosis caused by Saksenaea vasiformis. J Neurosurg 46:97.

Ellis JJ, Ajello L (1982) An unusual source for Apophysomyces elegans and a method for stimulating sporulation of Saksenaea vasiformis. Mycologia 74:144.

Ellis DH, Kominski GW (1985) Laboratory identification of Saksenaea vasiformis: a rare cause of zygomycosis in Australia. J Med Vet Mycol 23:137.

Farrow WM (1954) Tropical soil fungi. Mycologia 46:632.

Goos RD (1963) Further observations on soil fungi in Honduras. Mycologia 55:142.

Hay RJ, Cambell CK, Marshall WM, Rees BI, Pincott J (1983) Disseminated zygomycosis (mucormycosis) caused by Saksenaea vasiformis. J Infect 7:162.

Hodges CS (1962) Fungi isolated from southern forest tree nursery soils. Mycologia 54:221.

Joffe AZ, Borut SY (1966) Soil and kernel microflora of groundnut fields in Israel. Mycologia 58:629.

Koren G, Polacheck I, Kaplan H (1986) Invasive mucormycosis in a non-immunocompromised patient. J Infect 12:165.

Oberle AD, Penn RL (1983) Nosocomial invasive Saksenaea vasiformis infection. Am J Clin Pathol 80:885.

Patino JF, Mora R, Guzman MA, Rodriguez-Franco E (1984) Mucormycosis: a fatal case by Saksenaea vasiformis. World J Surg 8:419.

Pierce PF, Wood MB, Roberts GD, Fitzgerald RH, Robertson C, Edson RS (1987) Saksenaea vasiformis osteomyelitis. J Clin Microbiol 25:933.

Pritchard RC, Muir DB, Archer KH, Beith JM (1986) Subcutaneous zygomycosis due to Saksenaea vasiformis in an infant. Med J Aust 145:630.

Saksena SB (1953) A new genus of mucorales. Mycologia 46:426.

Torell J, Cooper BH, Helgeson NGP (1981) Disseminated Saksenaea vasiformis infection. Am J Clin Pathol 76:116. 